\title{
PROPOSTA DE IMPLEMENTAÇÃO DA FERRAMENTA PDCA PARA MELHORIAS NO SETOR DE RH EM UMA EMPRESA DE PRESTAÇÃO DE SERVIÇOS
}

\section{ARTIGO ORIGINAL}

DAMASCENO, Filipe Moreira ${ }^{1}$, BRASIL, Thiago Cerdeira ${ }^{2}$, ARAÚJO, Elanny Cristyna Lira $^{3}$, ROBERTO, José Carlos Alves ${ }^{4}$

DAMASCENO, Filipe Moreira. Et al. Proposta de implementação da ferramenta Pdca para melhorias no setor de rh em uma empresa de prestação de serviços. Revista Científica Multidisciplinar Núcleo do Conhecimento. Ano 06, Ed. 05, Vol. 05, pp. 28-47. Maio de 2021. ISSN: 2448-0959, Link de acesso: https://www.nucleodoconhecimento.com.br/administracao/implementacaoda-ferramenta, DOI: 10.32749/nucleodoconhecimento.com.br/administracao/implementacao-daferramenta

\section{RESUMO}

Este artigo é baseado em um estudo de caso realizado na Harpia Soluções em Serviços, que tem como objetivo analisar as estratégias adotadas pela área de recursos humanos. A pesquisa segue os fundamentos da metodologia, é descritiva, exploratória, qualitativa e bibliográfica, e é um meio de obter a cientificidade do conteúdo proposto. A pesquisa tem como objetivo analisar diversos aspectos que

${ }^{1}$ Graduando do curso de Administração.

2 Graduando do curso de Administração.

${ }^{3}$ Graduanda do curso de Administração.

${ }^{4}$ Mestrado profissional em Engenharia de produção. Especialização em Gestão em Logística empresarial. Graduação em Administração com Ênfase em Marketing.

$\mathrm{RC}: 84729$

Disponível em: https://www.nucleodoconhecimento.com.br/administracao/implementacao-daferramenta 
afetam as relações de trabalho, a comunicação e a qualidade do serviço. A ferramenta do ciclo PDCA que contribui para a qualidade geral do processo, pode promover melhorias significativas nos resultados organizacionais, identificar gargalos, reduzir gastos para aprimorar o uso de talentos, melhorar os serviços e diminuir o tempo de resposta. As melhorias propostas deixarão os colaboradores satisfeitos com o desempenho da atividade e trarão resultados positivos para a empresa.

Palavras-Chave: Serviços, terceirização, comunicação.

\section{INTRODUÇÃO}

Este artigo é um estudo de caso desenvolvido na empresa Harpia Soluções em Serviços que atua e realiza negócios no setor de terceirização de mão-de-obra. A pesquisa começa com um diagnóstico organizacional, que se embasa no uso de tecnologias utilizadas no aspecto interno com proprietários e funcionários para apontar que a empresa estudada precisa de uma estratégia de melhoria para o departamento de recursos humanos.

Mudanças no aspecto organizacional em parâmetros mundiais mudaram as perspectivas econômicas e sociais. Diante dessa turbulência, foi criado o objetivo geral de "Elevar os índices de qualidade dentro de uma empresa de prestação de serviços".

Em uma situação competitiva, descobrir novas tecnologias tornou-se crucial para uma gestão eficiente de recursos humanos. A gestão de recursos humanos é uma área que resolve problemas externos e internos em uma organização, estando ao seu encargo o papel crucial nas relações de trabalho como um todo.

As mudanças dentro deste setor, visam principalmente elevar os níveis de eficácia, uma vez que a mão-de-obra é o principal produto da empresa, os fatores que estão ao seu redor influências diretamente na qualidade dos serviços prestados, 
consequentemente afetando todo o desempenho da empresa, e sua relação com o consumidor final.

Fez-se então necessário o uso de uma ferramenta que fosse capaz de implementação das medidas previamente estabelecidas, adotou-se então o ciclo PDCA, uma metodologia focada na realização de metas em um processo de forma cíclica, de modo a focar desde o processo de planejamento, até o de verificação, onde serão identificadas as necessidades de eventuais mudanças.

Esta investigação divide-se em várias etapas, iniciando-se com um resumo, passando por uma breve introdução ao conteúdo a ser explicado e, em seguida, a base teórica do setor de recursos humanos, e os pontos que estão ligados à este. A seguir está o método utilizado para a elaboração deste artigo. Em suma, a empresa Harpia Soluções em Serviços será apresentada. Continuando com os resultados e discussões e, por fim, as considerações finais.

\section{FUNDAMENTAÇÃO TEÓRICA}

A partir da fundamentação teórica serão apresentados conceitos importantes que apoiam e contribuem para o tema, nomeadamente as melhorias do setor de Recursos Humanos. Portanto, do ponto de vista analítico, além de apoiar conceitos relacionados e a aplicação de modelos ou tipos relacionados a organizações, ambientes e indivíduos, do ponto de vista da pesquisa, os argumentos e características do tema são determinados por alguns autores que estudam o tema proposto.

Este artigo discute as melhorias no setor de recursos humanos, tema muito relevante para o mercado e o crescimento econômico do Brasil. Ribeiro (2016), afirma que a base do sucesso está no desenvolvimento de uma estratégia de recursos humanos eficaz, que interligue os colaboradores, conheça e administre seu potencial e seu trabalho, os valores e a visão da organização.

RC: 84729

Disponível em: https://www.nucleodoconhecimento.com.br/administracao/implementacao-daferramenta 
A fundamentação teórica desta pesquisa fundamenta-se no tema da área do conhecimento, na definição do tema e nas principais referências do conteúdo proposto.

\subsection{CONCEITO DE RECURSOS HUMANOS}

Tendo em vista a mão de obra, o trabalhador era visto como um recurso mecânico que seguia um padrão pré-estabelecido com foco no alcance de metas, por muitos anos esse entendimento se perpetuou na visão estratégica das organizações, até que se notasse a necessidade de se dividir os recursos materiais e o pessoal, agregando ao colaborador valor, e valorizando os processos de relações dentro das instituições a partir de políticas organizacionais mais orgânicas e menos mecanicistas. Para Cruz e Santana (2015) o departamento de Recursos Humanos é responsável pelo notável desenvolvimento da organização e pelo aporte de capital intelectual, que simboliza a importância dos fatores humanos em plena era da informação, a área de recursos humanos tornou-se um dos fatores mais importantes para a vantagem competitiva e sustentável de uma empresa, foi incorporada a estratégia e não se separou dela.

Essa estratégia organizacional apresentada de forma importante para o alcance de resultados na organização é o principal motor da transformação, pois não só determina quem vai trabalhar na empresa, mas também determina auxiliar o coordenador a projetar e descrever a posição, avaliar o desempenho, política de remuneração, salários e benefícios, cultura voltada para a performance, ações estratégicas, treinamento e desenvolvimento, endomarketing e comunicação interna eficaz e retenção de talentos.

\subsubsection{AS FUNÇÕES DA ÁREA DE RECURSOS HUMANOS}

O departamento de recursos humanos na gestão organizacional é responsável por manter a vitalidade da empresa. A forma de organização e gestão de pessoas está em um processo de grandes mudanças à escala global, provocada por alterações

RC: 84729

Disponível em: https://www.nucleodoconhecimento.com.br/administracao/implementacao-daferramenta 
importantes na organização do trabalho, na relação entre a organização e o pessoal e na visão das pessoas sobre a relação com o trabalho e o comportamento do mercado de trabalho.

Para Nóbrega e Sá (2010), nos últimos tempos constata-se a evolução teórica no tocante à discussão sobre o papel da área de recursos humanos que antes era vista apenas com um departamento funcionalista, e que hoje atua de forma mais estratégica no cenário das organizações.

Neste aspecto, o setor de Recursos Humanos passa a ter maior importância dentro das organizações, uma vez que se tem a percepção de que as relações interpessoais afetam diretamente $\mathrm{e}$ indiretamente a afetividade das funções e 0 pleno funcionamento das organizações.

\subsubsection{POLÍTICA ORGANIZACIONAL DE RECURSOS HUMANOS}

A criação dessas políticas, seja para auxiliar na tomada de decisões, definir regras ou consolidar e disseminar as características da organização, só pode ter continuidade quando o campo envolvido estiver em evolução e as ações realizadas forem devidamente monitoradas com base nesses comportamentos. O objetivo deste controle é avaliar se as diretrizes são seguidas corretamente. Caso as diretrizes não sejam seguidas, podem ser reavaliadas e modificadas para garantir o cumprimento dos objetivos da empresa.

Para Siqueira, (2014) podemos definir políticas organizacionais como estabelecer os princípios de comportamento corporativo, que é um curso geral de ação, algumas das quais práticas funcionam juntas de uma forma construtiva para atingir um determinado objetivo. Dentro do setor de Recursos Humanos, a ineficácia de diretrizes organizacionais, ou até mesmo a falta de compreensão destas, tende a gerar uma série de erros, que uma vez cometidos, afetam toda uma cadeia de produção. 
Tendo como exemplo, um processo de recrutamento e seleção quando não executado de acordo com as normas previstas dentro da política organizacional de uma empresa, compromete a qualidade dos serviços no futuro, e consequentemente o desempenho geral da empresa.

\subsubsection{GESTÃO DA QUALIDADE NO SÉCULO XXI}

Em tese gestão da qualidade busca garantir a consistência da organização, produto ou serviço. Tendo quatro partes principais: plano de qualidade, garantia de qualidade, controle de qualidade e melhoria de qualidade. A gestão da qualidade não está centrada apenas na qualidade dos produtos e serviços, mas também nos meios para alcançá-la. Portanto, a gestão da qualidade usa processos, bem como garantia do produto e controle de qualidade para obter uma qualidade mais consistente.

Para Silva (2015) isso não significa apenas controle de produção, qualidade interna de bens e serviços, aplicação individual de ferramentas e métodos de gestão ou assistência técnica adequada, mas também tem amplas perspectivas. Portanto, podemos definir qualidade como adequação para o uso final, ou o grau em que o produto ou serviço desempenha sua função pretendida.

\subsubsection{GESTÃO POR COMPETÊNCIA}

Trata-se de um sistema na área da gestão de recursos humanos que visa identificar e gerir características profissionais que possam trazer maior rentabilidade à empresa, identificar pontos de excelência e oportunidades de melhoria, preencher lacunas e aumentar o conhecimento.

O modelo de gerenciamento de capacidade sempre será conceitualmente enviesado e deve ser difícil de medir, mas à medida que o processo de identificação de perfis progride, o gerenciamento será melhor. Castro, (2019) afirma que independentemente do modo de gestão do capital humano que ele escolher, ele deve considerar que as

RC: 84729

Disponível em: https://www.nucleodoconhecimento.com.br/administracao/implementacao-daferramenta 
pessoas são o elemento organizacional mais importante para a criação de valor e riqueza.

Essas competências quando bem geridas, aproveitam o que há de melhor no profissional, além de explorar positivamente fatores antes não identificados dentro do corpo de funcionários em uma organização; competências mal geridas, tornam-se em perda de capital intelectual para a empresa como um todo.

\subsubsection{INDICADOR CHAVE DE DESEMPENHO}

Essa ferramenta de gestão utiliza do levantamento de dados para realizar a medição de uma organização ou de um processo e consequente desempenho e nível de sucesso, focando no "como" e indicando se o processo da empresa é bom para atingir seus objetivos.

Bonel (2017) define o principal objetivo dos Indicadores chave de desempenho, ou KPI's (Key Performance Indicator) com o papel de acompanhar se as ações implementadas estão obtendo o resultado esperado ou não, de acordo com as diretrizes definidas.

Como o mencionado no tópico 2.1.2 "Política Organizacional de Recursos Humanos", a adoção de diretrizes busca estabelecer padrões a serem seguidos na realização dos processos, por sua vez, a utilização desses indicadores busca identificar se as diretrizes têm sido cumpridas, e além disso, analisar a eficácia de sua implementação, podendo ser padrão de análise para eventuais mudanças nas políticas organizacionais.

\subsubsection{FERRAMENTA EMPLOYER BRANDING}

Esta estratégia visa fortalecer os aspectos positivos do trabalho na organização, valorizar a sua imagem e atrair verdadeiros talentos para o quadro de colaboradores. Portanto, se bem executada, os colaboradores pensarão que a empresa é uma RC: 84729

Disponível em: https://www.nucleodoconhecimento.com.br/administracao/implementacao-daferramenta 
excelente opção para suas carreiras, uma oportunidade de desenvolver seu potencial produtivo e melhorar seu nível profissional.

Clavery (2020), afirma que as organizações precisam estar mais focadas na mudança da imagem dos candidatos, pois já é possível perceber seus posicionamentos mais positivos. Como resultado, candidatos talentosos competem pelas vagas disponíveis, enquanto os funcionários existentes lutam para permanecer na equipe gerando maior aproveitamento das competências, e incentivando constante aperfeiçoamento profissional.

\subsubsection{CHATBOT E SUA APLICABILIDADE}

Uma vez bem estruturado do ponto de vista estratégico, o setor de Recursos Humanos precisa integrar toda a organização de forma dinâmica e eficaz, uma das formas de alcançar esse dinamismo, é por meio da redução do tempo de resposta de questões do dia-a-dia, além da facilidade de acesso às informações básicas da empresa por parte dos colaboradores.

Para Cruz, Alencar e Schmitz (2018), organizações inovadoras descobrem que os assistentes virtuais são uma ferramenta poderosa para obter novas vantagens competitivas, pois podem tornar os assistentes virtuais uma parte integrante. Esta ferramenta busca assim, inovar práticas organizacionais, e agregar valor aos serviços.

\subsubsection{FERRAMENTA PDCA}

Desta forma, a implementação de tais estratégias e ferramentas de gestão, depende única e exclusivamente de um planejamento embasado e estruturado. O ciclo PDCA, surge como um método de gerenciamento iterativo de quatro etapas para controlar e melhorar continuamente os processos e produtos, sendo estes Planejar, Checar, Controlar e Agir, ferramenta essa que deve ser utilizada de forma cíclica para que obtenha os resultados esperados.

RC: 84729

Disponível em: https://www.nucleodoconhecimento.com.br/administracao/implementacao-daferramenta 
De acordo com Lira (2020), é um método amplamente utilizado para controlar as atividades organizacionais (especialmente aquelas relacionadas à melhoria). Silva (2015) afirma que o ciclo PDCA descreve os procesos com base no processo de verificação, como fazer mudanças, incluindo o planejamento e implementação de mudanças e, portanto, verificar se há melhorias esperadas.

\section{MATERIAIS E MÉTODOS}

No campo do ensino, metodologia é estabelecer métodos de investigação, pesquisa para atingir seus objetivos. Para Furlanetti e Nogueira (2015, p. 20) "A metodologia é a sequência dos procedimentos necessários que descrevem a forma como será realizada a pesquisa, ela responderá como é possível atingir os objetivos.

Assim, este trabalho utilizará diferentes ferramentas quali-quantitativas na busca de informações para implementação de métodos que ajudem a determinar a solução mais adequada e com foco na formulação de uma proposta adequada aos problemas anteriormente expressos na empresa Harpia Soluções em Serviços.

\subsection{PROCEDIMENTOS METODOLÓGICOS}

Processo metodológico, representa a escolha do método dedutivo ou método indutivo, e o tipo de pesquisa utilizada como ferramenta, que pode ser: experimento, teoria, exploração, interpretação, bibliografia, literatura, qualitativa, quantitativa e etc. Segundo Silva; Sousa e Lopes $(2013$, p. 8) "Na prática, haverá uma combinação das tipologias de pesquisa. Por exemplo, quando se faz uma abordagem quantitativa deve-se, também, utilizar a abordagem qualitativa para esclarecer".

Os processos e ferramentas a serem aplicados, têm como base a coleta dos dados feitos no aspecto quali-quantitativo em relação à qualidade dos serviços prestados na empresa, utilizando-se deste método para mensurar resultados e formular objetivos. 


\subsubsection{QUANTO A NATUREZA}

Vergara (2013) categoriza os tipos de pesquisa de acordo com as metas e objetivos da pesquisa.

Partindo de uma natureza aplicativa, esta pesquisa usa uma abordagem híbrida porque primeiro realiza a análise de dados por meio da coleta de informações e, em seguida, realiza uma análise mais ampla por meio da observação direta, para então estipular metas e objetivos.

\subsubsection{QUANTO AOS FINS}

O objetivo da pesquisa é esclarecer o desenvolvimento da intenção do pesquisador a partir do percurso teórico até o resultado a ser alcançado. Segundo Rauen (2018) esse objetivo envolve o uso de conhecimentos já disponíveis para determinadas aplicações práticas, de forma que os resultados obtidos possam ser utilizados imediatamente na resolução de problemas do mundo real.

Quanto aos fins, esta pesquisa busca aplicar resoluções, conectando cada um dos problemas encontrados à uma solução direta com foco nos resultados a serem obtidos, a partir do conhecimento teórico aplicado na prática.

\subsubsection{QUANTO AOS MEIOS}

Quanto aos meios, se trata da classificação como um estudo de campo será conduzido em laboratório, documentário, bibliografia, experimento, pesquisa-ação e estudo de caso.

Para Santanchê (2015, p. 122), "O estudo de caso, consiste no estudo profundo e exaustivo (intensivo), de um ou poucos objetivos, de maneira que permita seu amplo e detalhado conhecimento".

RC: 84729

Disponível em: https://www.nucleodoconhecimento.com.br/administracao/implementacao-daferramenta 
Utilizando o estudo de caso, este projeto busca compreender alguns fenômenos e aspectos pertinentes aos problemas encontrados, identificar os fatores que contribuem para a ocorrência do fenômeno, explicando sua causa e solucionar necessidades da empresa estudada.

\subsection{CARACTERÍSTICAS DA EMPRESA}

A Harpia Soluções em Serviços, é uma empresa de médio porte prestadora de serviços terceirizados sediada há mais de 5 anos na cidade de Manaus, a empresa está presente em diversos segmentos, desde escolas, hospitais, clínicas, shoppings, condomínios e empresas, com atividades que vão desde agentes de portaria, auxiliares de serviços gerais, controle de acesso e paisagismo, a empresa tem buscado expandir suas atividades e busca por uma estrutura consolidada no nicho de atuação.

\section{RESULTADOS E DISCUSSÕES}

De acordo com a pesquisa na etapa de diagnóstico da organização, verifica-se que a empresa estudada possui pontos básicos em cada área funcional da organização, onde podemos identificar áreas mais críticas e que necessitam de intervenção a partir da implementação de ações interventivas em um setor mas que visam impactar de forma positiva a organização como um todo a partir do processo de análise e verificação, partindo para a implementação e uso de ferramentas. Como podemos averiguar no Gráfico 01.

RC: 84729

Disponível em: https://www.nucleodoconhecimento.com.br/administracao/implementacao-daferramenta 
Gráfico 01: Medição de desempenho.

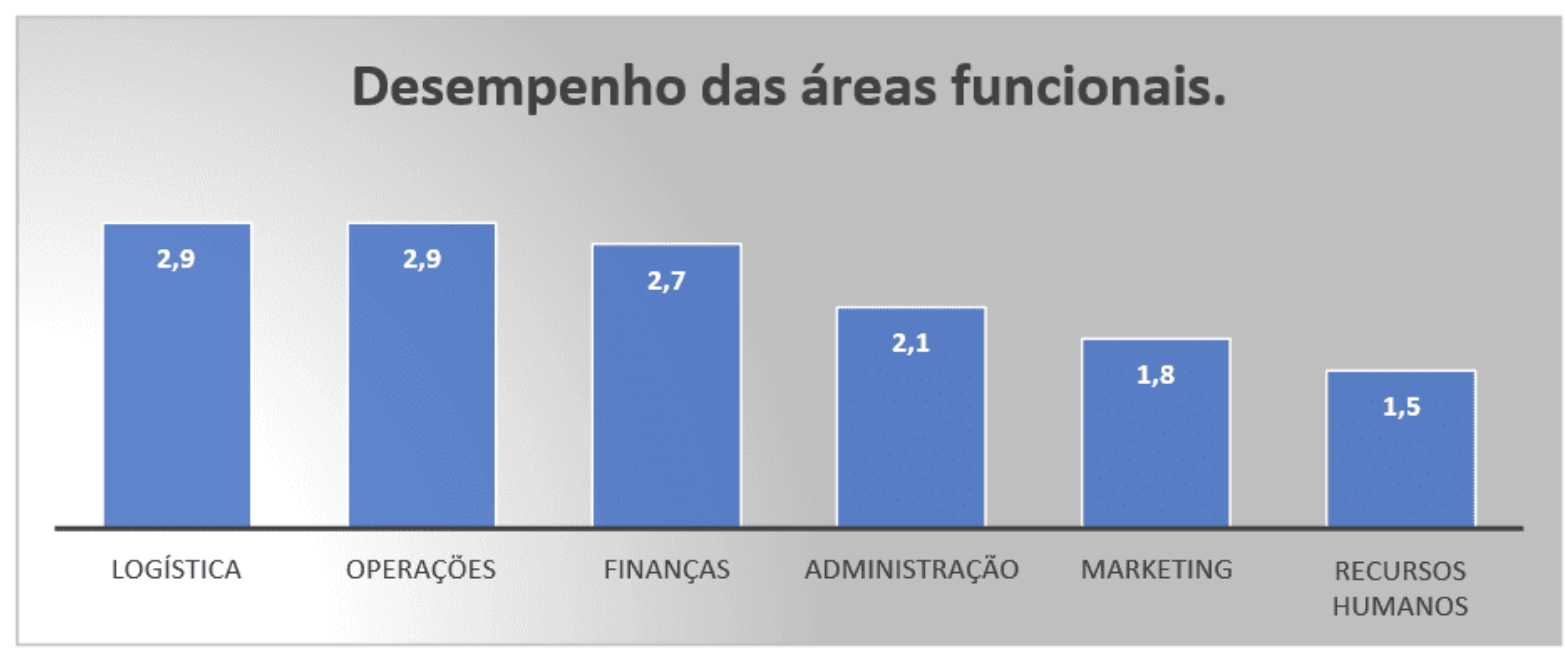

Fonte: Elaborado pelos autores com base na coleta de dados, 2020.

Observa-se que a empresa possui áreas de logística e operações com o melhor desempenho; finanças, administração e marketing são áreas de desempenho média. Conforme mostrado na figura, o setor de Recursos Humanos é considerado a área mais crítica.

Quadro 1: Área funcional de Recursos Humanos.

\begin{tabular}{|l|l|l|l|l|l|l|}
\hline AREA FUNCIONAL & \multicolumn{3}{|c|}{ NIVEL OU GRAU DE AVALIAÇÃo } \\
\hline & Pont & Pont & Pont & Pont & Pont \\
\hline \multirow{2}{*}{ RECURSOS HUMANOS } & 0 & 0 & 0 & 0 & 0 \\
\hline & muit & forte & médi & fraco & muit \\
\hline & 0 & 4 & o 3 & 2 & 0 \\
\hline 1 & forte & & & & fraco \\
\hline 2 & Horas extras de trabalho & 5 & & & & 1 \\
\hline
\end{tabular}

RC: 84729

Disponível em: https://www.nucleodoconhecimento.com.br/administracao/implementacao-daferramenta 


\begin{tabular}{|c|c|c|c|c|c|c|}
\hline 3 & $\begin{array}{l}\text { Treinamento de acordo com o posto } \\
\text { onde o serviço é prestado }\end{array}$ & & & & $X$ & \\
\hline 4 & $\begin{array}{l}\text { Turnover dos colaboradores que } \\
\text { prestam serviços externos }\end{array}$ & & & & & $\mathrm{x}$ \\
\hline 5 & $\begin{array}{l}\text { Recrutamento e Seleção de mão de } \\
\text { obra } \\
\text { qualificada }\end{array}$ & & & & & $\mathrm{x}$ \\
\hline 6 & $\begin{array}{l}\text { Avaliação do Clima Organizacional } \\
\text { entre os colaboradores }\end{array}$ & & & & & $\mathrm{x}$ \\
\hline 7 & $\begin{array}{l}\text { Aproveitamento de talentos entre } \\
\text { os colaboradores }\end{array}$ & & & & & $x$ \\
\hline 8 & Plano de carreira dentro da empresa & & & & & $x$ \\
\hline 9 & $\begin{array}{l}\text { Medição do nível de satisfação dos } \\
\text { clientes }\end{array}$ & & & & $\mathrm{x}$ & \\
\hline $\begin{array}{l}1 \\
0\end{array}$ & $\begin{array}{l}\text { Comunicação de acordo com a } \\
\text { hierarquia dentro dos postos de trabalho }\end{array}$ & & & $x$ & & \\
\hline \multicolumn{2}{|r|}{ TOTAL $(\Sigma)$} & 0 & 0 & 3 & 6 & 6 \\
\hline \multicolumn{2}{|r|}{ MÉDIA POR GRAU (POR COLUNA) } & 0 & 0 & 0.3 & 0.6 & 0.6 \\
\hline \multicolumn{2}{|r|}{ DESEMPENHO DA ÁREA ( $\Sigma)$ TOTAL } & \multicolumn{5}{|l|}{1.5} \\
\hline
\end{tabular}

Fonte: Elaborado pelos autores com base na coleta de dados, 2020.

De acordo com os principais fatores mostrados no Quadro 01, existem alguns itens na empresa Harpia Soluções em Serviços, na área de recursos considerados muito importantes para que a qualidade dos serviços prestados seja considerada satisfatória, estes fatores vão desde os processos de comunicação que devem ser melhorados, o nível de capacitação dos colaboradores e à uma política organizacional mais efetiva. Podemos assim considerar que problema da pesquisa é: Como a criação 
de novas estratégias de Recursos Humanos pode elevar os índices de qualidade dos serviços prestados?

\subsection{PLANEJAMENTO DE AÇÕES}

O plano de ação inclui etapas de todo o processo a serem implementadas descrevendo as mudanças dentro das práticas da organização e como seus setores devem atuar de forma estratégica para que os objetivos sejam atingidos dentro de periódicos.

Quadro 2: Quadro de ações interventivas.

\begin{tabular}{|c|c|c|c|c|}
\hline & Ações Interventivas & Cronologia & Duração & Custo \\
\hline 01 & $\begin{array}{l}\text { Identificar fatores chave que } \\
\text { influenciam na qualidade. }\end{array}$ & Junho/2021 & Três dias. & $\mathrm{R} \$ 500,00$ \\
\hline 02 & $\begin{array}{l}\text { Implementação da ferramenta } \\
\text { employer branding no setor de } \mathrm{RH} \text {. }\end{array}$ & & $\begin{array}{l}\text { Ima } \\
\text { emana. }\end{array}$ & $\{\$ 1000,00$ \\
\hline 03 & $\begin{array}{l}\text { Formular uma política organizacional } \\
\text { com foco no relacionamento. }\end{array}$ & Julho/2021 & $\begin{array}{l}\text { Uma } \\
\text { semana. }\end{array}$ & $\mathrm{R} \$ 1000,00$ \\
\hline 04 & $\begin{array}{l}\text { Criação de um chatbot para } \\
\text { solucionar questões do } \mathrm{RH} \text {. }\end{array}$ & Julho/2021 & $\begin{array}{l}\text { Quatro } \\
\text { dias. }\end{array}$ & $\mathrm{R} \$ 1000,00$ \\
\hline 05 & $\begin{array}{l}\text { Desenvolvimento de } \\
\text { estratégias para retenção de talentos. }\end{array}$ & Agosto/2021 & $\begin{array}{l}\text { Uma } \\
\text { semana. }\end{array}$ & $\mathrm{R} \$ 1000,00$ \\
\hline 06 & $\begin{array}{l}\text { Elaboração do programa } \\
\text { interno de capacitação. }\end{array}$ & Agosto/2021 & $\begin{array}{l}\text { Três } \\
\text { Semanas. }\end{array}$ & $\mathrm{R} \$ 2000,00$ \\
\hline
\end{tabular}

Fonte: Formulado por autores, 2021.

A proposta de solução para cada etapa é formulada da seguinte a partir da implementação do ciclo PDCA que consiste em um método interativo de gestão de quatro passos, utilizado para o controle e melhoria contínua de processos e produtos.

$\mathrm{RC}: 84729$

Disponível em: https://www.nucleodoconhecimento.com.br/administracao/implementacao-daferramenta 
Segundo Guerra e Cavalcanti (2020, p. 5) "O ciclo PDCA estabelece quatro etapas para o desenvolvimento de projetos, produtos e processos, de forma continua: Plan, Do, Check e Act, em um processo sucessivo, com a repetição cíclica dessas etapas".

\subsubsection{IDENTIFICAR FATORES QUE INFLUENCIAM NA QUALIDADE:}

O processo de identificação de fatores chave dentro da área da qualidade mostram gargalos em processos e atividades que podem ser melhorados e reelaborados, 0 conhecimento quanto à estes fatores possibilita ainda a formulação de políticas organizacionais mais efetivas, uma vez que estarão embasadas de forma coesa à realidade em que a empresa se encontra. Os fatores aqui identificados não estarão necessariamente ligados de forma direta, mas também indireta aos problemas identificados na fase de diagnóstico.

Quadro 3: PDCA - Identificar fatores chave que influenciam na qualidade.

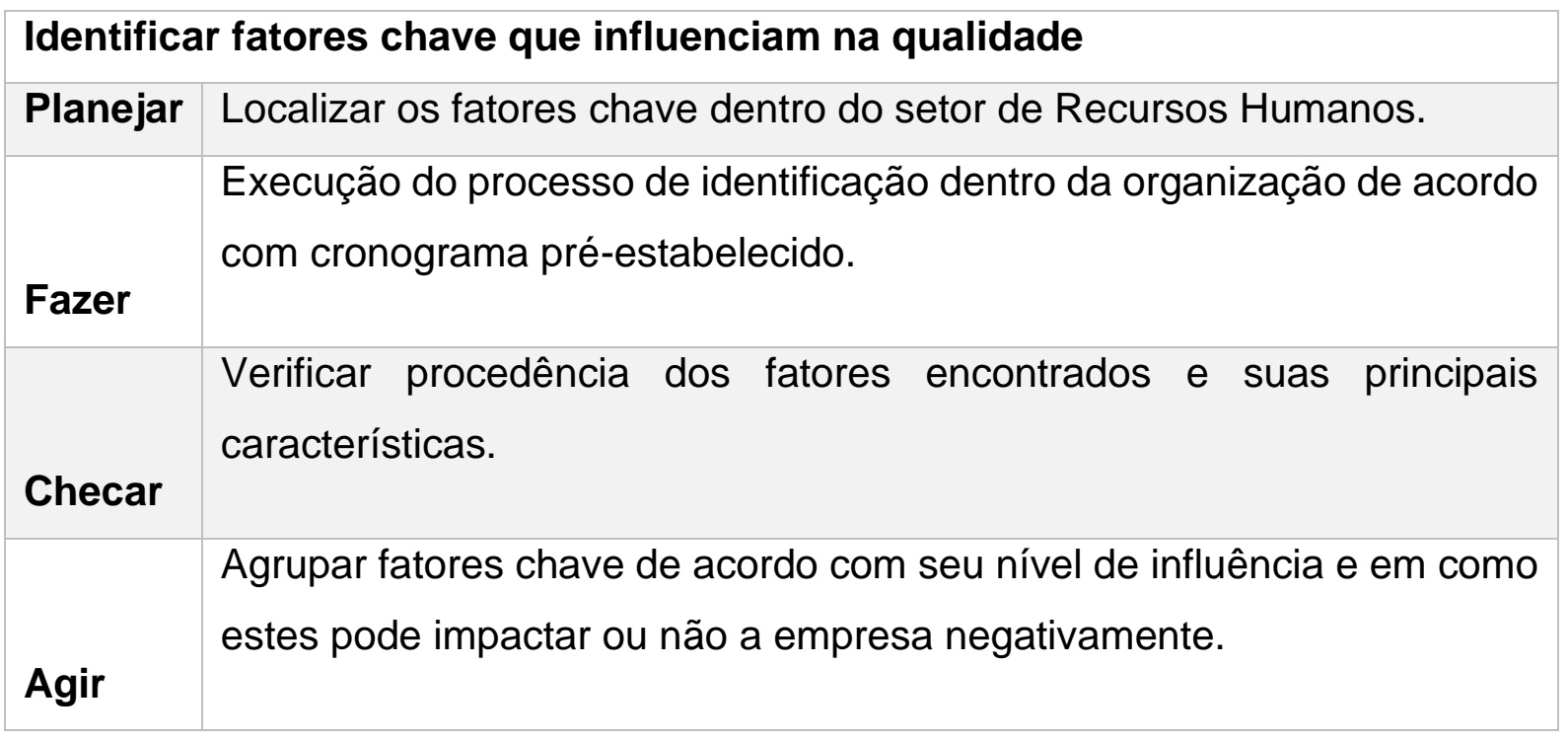

Fonte: Elaborado por autores, 2021. 


\subsubsection{IMPLEMENTAÇÃO DA FERRAMENTA EMPLOYER BRANDING NO SETOR DE RH:}

Esta etapa busca implementar a "marca do empregador" no setor de Recursos Humanos da empresa, utilizando um conjunto de técnicas e ferramentas para gerar uma percepção positiva do mercado a respeito da empresa como local de trabalho.

Esta estratégia visa fortalecer os aspectos positivos do trabalho na organização, valorizar a sua imagem e atrair verdadeiros talentos para o quadro de colaboradores.

Quadro 4: PDCA - Implementação da ferramenta Employer Branding no setor de RH.

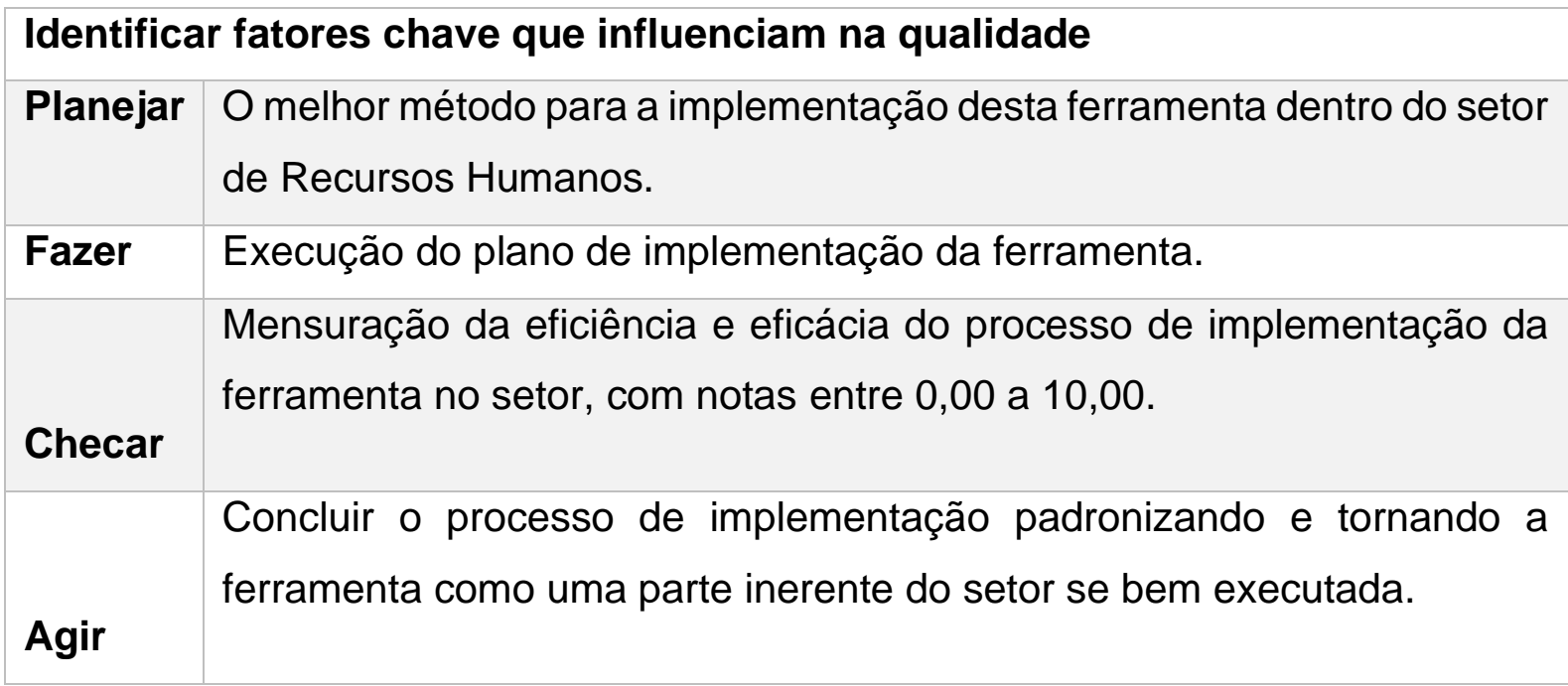

Fonte: Formulado por autores, 2021.

\subsubsection{FORMULAR UMA POLÍTICA ORGANIZACIONAL COM FOCO NO RELACIONAMENTO:}

As políticas organizacionais constituem orientação administrativa para impedir que os colaboradores desempenhem funções indesejáveis ou ponham em risco o sucesso de funções específicas. Estas formuladas para o relacionamento entre empresa e colaborador, visam direcionar os esforços na qualificação constante dos integrantes,

RC: 84729

Disponível em: https://www.nucleodoconhecimento.com.br/administracao/implementacao-daferramenta 
bem como na criação de um ambiente de trabalho que promova o comprometimento e estimule a motivação dele.

Quadro 5: PDCA - Formular uma política organizacional com foco no relacionamento.

\section{Formular uma política organizacional com foco no relacionamento}

Definição de pontos relevantes e a identificação de fatores importantes.

\section{Planejar}

Reunião de elaboração da nova política com equipe consultora e gestores.

Checar Aprovação e formalização para a implementação da mesma.

Formatação do documento para colocar em prática as novas diretrizes elaboradas.

\section{Agir}

Fonte: Formulado por autores, 2021.

\subsubsection{CRIAÇÃO DE UM CHATBOT PARA SOLUCIONAR QUESTÕES DO RH:}

Um chatbot é um software capaz de manter uma conversa com um usuário humano em linguagem natural, por meio de aplicativos de mensagens, sites, e outras plataformas digitais. A criação do mesmo, tem como benefícios para a empresa a capacidade de oferecer suporte imediato e de qualidade aos clientes e colaboradores, reduzindo a necessidade de manutenção de uma equipe grande para esse atendimento. Isso permite que os colaboradores se concentrem em tarefas que exigem planejamento e estratégia, além de reduzir o tempo de respostas de questões inerentes ao setor de Recursos Humanos. 
Quadro 6: PDCA -Criação de um chatbot para solucionar questões do $\mathrm{RH}$.

\section{Criação de um chatbot para solucionar questões do RH}

\begin{tabular}{|l|l|}
\hline Planejar & $\begin{array}{l}\text { Definição do propósito do uso da ferramenta chatbot dentro do setor de } \\
\text { Recursos Humanos. }\end{array}$ \\
\hline Fazer & $\begin{array}{l}\text { Formulação de uma lista com todas as funções requeridas para criação } \\
\text { de conteúdo da conversa escolhendo os canais e plataformas. }\end{array}$ \\
\hline Checar & $\begin{array}{l}\text { Verificação do funcionamento do software e da efetividade de seu uso no } \\
\text { dia-a-dia dos colaboradores. }\end{array}$ \\
\hline Agir & $\begin{array}{l}\text { Interação através do chatbot e análise periódica para eventuais } \\
\text { mudanças na plataforma. }\end{array}$ \\
\hline
\end{tabular}

Fonte: Formulado por autores, 2021.

\subsubsection{DESENVOLVIMENTO DE ESTRATÉGIAS PARA RETENÇÃO DE TALENTOS:}

A retenção de talentos é o conjunto de ações com o objetivo de manter na organização ótimos colaboradores, com bons talentos, através das estratégias de reconhecimento, oferta de benefícios corporativos, ações de integração ao ambiente de trabalho. A retenção desses profissionais leva a inúmeras vantagens, destacando- se o crescimento da empresa.

Quadro 7: PDCA - Desenvolvimento de estratégias para retenção de talentos.

\section{Desenvolvimento de estratégias para retenção de talentos:}

Implementar práticas e políticas adotadas para o reconhecimento de talentos.

RC: 84729

Disponível em: https://www.nucleodoconhecimento.com.br/administracao/implementacao-daferramenta 
Planejar

Fazer Execução do plano de retenção de talentos.

Verificação do engajamento da produtividade e eficiência dos colaboradores.

Checar

Será aprimorado novos planos de retenção para cumprir todas as metas definidas;

\section{Agir}

Fonte: Formulado por autores, 2021.

\subsubsection{ELABORAÇÃO DO PROGRAMA INTERNO DE CAPACITAÇÃO:}

A elaboração de programas internos de capacitação ou treinamento, além de internos são imprescindíveis para o ótimo funcionamentos dos colaboradores dentro da atividade que the propõe a fazer, ou seja, um programa interno de capacitação dos funcionários é um planejamento feito pela organização que visa o desenvolvimento profissional dos colaboradores por meio das orientações certas. A capacitação se torna benefício oferecido ao funcionário, pois é ele que irá usufruir dessa capacitação e aprimoramento, para o crescimento de si e de seu negócio. Afinal, profissionais melhores capacitados trabalham melhor e fornecem resultados mais satisfatórios.

Quadro 8: PDCA - Elaboração do programa interno de capacitação.

\section{Elaboração do programa interno de capacitação.}

\begin{tabular}{|c|c|}
\hline Planejar & $\begin{array}{l}\text { O melhor método desta implementação de capacitação para o } \\
\text { desenvolvimento profissional dos colaboradores. }\end{array}$ \\
\hline Fazer & Programa de treinamento. \\
\hline & $\begin{array}{l}\text { Verificação da execução das atividades conforme sua } \\
\text { capacitação. }\end{array}$ \\
\hline
\end{tabular}

RC: 84729

Disponível em: https://www.nucleodoconhecimento.com.br/administracao/implementacao-daferramenta 
Concluir o processo de padronização desse programa de capacitação Agir melhorando as tarefas executadas pelos colaboradores.

Fonte: Formulado por autores, 2021.

\subsubsection{ANÁLISE DAS AÇÕES INTERVENTIVAS.}

Ao final do processo de implementação dos pontos ações acima citadas, uma nova análise deve ser realizada de maneira periódica, uma vez que a ferramenta utilizada se trata de um ciclo, em busca de melhorias, por sua vez, o resultado desta análise colocará em evidência a necessidade de eventuais mudanças a serem tomadas, seja por motivos de aplicações que não obtiveram o resultado esperado, ou por mudanças nos ambientes internos e externos à organização. Essas análises deverão utilizar dos mesmos recursos abordados na fase de diagnóstico, para que o processo de tomada de decisão ocorra de maneira coerente à aquilo que se espera, de modo a manter o setor de Recurso Humanos em constantes aperfeiçoamento, no contexto estratégico, possibilitando assim melhor compreensão do que se passa na empresa e gerando novas metas e objetivos.

\section{CONSIDERAÇÕES FINAIS}

Diante das informações coletadas na empresa Harpia Soluções em Serviços, a análise feita possibilitou demonstrativos da baixa eficiência na área de Recursos Humanos, dados esses observados a partir de questionários aplicados na organização. Foi então discutido em equipe formas de melhorias para cada uma das falhas encontradas, com o objetivo de tornar mais eficiente os processos internos deste setor, tendo em vista tratar-se da área mais crítica, para garantir soluções através de ferramentas da qualidade.

Com base na pesquisa realizada, os resultados e discussões demonstraram que a área de $\mathrm{RH}$, deve abranger uma devida atenção por parte dos gestores, pois o capital RC: 84729

Disponível em: https://www.nucleodoconhecimento.com.br/administracao/implementacao-daferramenta 
intelectual é de suma importância em uma empresa, e deve ser levado em consideração. O desenvolvimento dos colaboradores, traz consequentemente a sua valorização no mercado, contribuindo para o crescimento da organização, além de beneficiar a retenção de talentos. Para a atribuição de melhorias nesse departamento, foi levado em consideração diversos fatores e apontamentos a respeito da empresa estudada.

A respeito de determinados itens a serem melhorados, a primeira etapa era a de identificar a área mais afetada por meio da ferramenta de medição de desempenho, desvendando-se então, a necessidade de capacitação e desenvolvimento na área de talentos humanos, por meio de implementação de programas para tornar capaz o preparo adequado e qualificado dos colaboradores.

Foi elaborado um quadro de ações interventivas, onde nele é possível identificar o planejamento de ações a serem implementadas, descrevendo as mudanças das práticas da organização. A proposta de solução para cada etapa do quadro de ações interventivas, foi feita a partir da implementação do ciclo PDCA, que consiste em um método interativo de gestão de quatro passos, utilizado para a melhoria contínua de processos.

Para o processo de melhorias com relação a interação entre a empresa e o colaborar, optou-se pela busca de políticas voltadas ao relacionamento, além da adoção de estratégias que focam na integração foi também implementado o uso do software Chatbot, estes trarão benefícios como melhorar a experiência dos funcionários, facilitando uma troca eficiente de informações de forma ágil e segura. Tratando-se de métodos altamente eficazes.

Tendo em vista os aspectos observados, a área de recursos humanos é a peça fundamental para a Harpia, esse suprimento possibilitou o bom andamento da empresa, buscando facilitar e ajudar no desempenho de seus processos e de seus colaboradores, através de ferramentas que beneficiará o desempenho interno da

RC: 84729

Disponível em: https://www.nucleodoconhecimento.com.br/administracao/implementacao-daferramenta 
organização. Dessa maneira, foram desenvolvidas estratégias, analisando seus custos e recursos. Assim foi possível observar que as melhores ideias trouxeram resultados significativos para a organização.

\section{REFERÊNCIAS}

BONEL, Cláudio. AFINAL, O QUE É BUSINESS INTELLIGENCE?. Brasil: Edição do Autor, 2017.

CASTRO, Rita de Cássia Marques Lima de. APRENDIZAGEM ORGANIZACIONAL E GESTÃO DO CONHECIMENTO. São Paulo: Editora SENAC, 2019.

CLAVERY, Suzie. ISSO É EMPLOYER BRANDING?!. São Paulo: Leader, 2020.

CRUZ, Leôncio Teixeira; ALENCAR, Antonio Juarez; SCHMITZ Eber Assis. ASSISTENTES VIRTUAIS INTELIGENTES E CHATBOTS. Rio de Janeiro: Brasport, 2018.

CRUZ, Tamires Assis; SANTANA, Lidia Chagas. RECURSOS HUMANO S: PRESENTE NAS ORGANIZAÇÕES MAS DESCONHECIDO. $2^{\circ}$ Ed. Salvador: RIC Cairu, 2015.

FURLANETTI, A.C; NOGUEIRA, A.S. METODOLOGIA DO TRABAL HO CIENTÍFICO. 2ํㅡ. Ed. São Paulo: Clube de Autores, 2015. p.15

LIRA, Elisa Granha. ESTUDO DE TEMPOS E MOVIMENTOS: UMA ABORDAGEM LEAN PARA AUMENTAR A EFICIÊNCIA DE PROCESSOS FÍSICOS E DIGITAIS. Belo Horizonte: Edição do Autor, 2020.

GUERRA, Maria das Graças Gonçalves Vieira; CAVALCANTI, Lourdes Maria Rodrigues. USO DA ANÁLISE SWOT E DO CICLO PDCA PARA AVALIAÇÃO. 1 Ed. Curitiba: Appris, 2020. 
NÓBREGA, Fernanda de Araújo; SÁ, Maria Auxiliadora Diniz de. PRÁTICAS DE RECURSOS HUMANOS E SUA INFLUÊNCIA NA VALORIZAÇÃO HUMANA NO TRABALHO: realidade ou apenas discurso?. Rio de Janeiro: EnANPAD, 2010.

RAUEN, Fábio. ROTEIRO DE INVESTIGAÇÃO CIENTÍFICA. 1ํEd. São Paulo: Clube de Autores, 2018.

RIBEIRO, Renato Vieira. ESTRATÉGIA EMPRESARIAL E DE RECURSO S HUMANOS. Brasil, IESDE, 2016.

SANTANCHÉ, André. CONSTRUÇÃO DO CONHECIMENTO E METODOLOGIA CIENTÍFICA. Salvador: FG, 2015. p. 122

SILVA, José Claret Theodoro. GESTOR DA QUALIDADE. São Paulo: Edição do Autor, 2015.

SILVA, Maurício Correa et al. (orgs). PROCEDIMENTOS METODOLÓGICOS PARA A REALIZAÇÃO DA PESQUISA EM CONTABILIDADE GOVERNAMENTAL: Uma abordagem teórica e prática. Rio Grande do Norte: Universidade UFRN, 2013. p.8

SILVA, Raiane Rodrigues da. A IMPORTÂNCIA DO SETOR DE RECURSOS HUMANOS NO CONTEXTO DA ESTRATÉGIA DA ORGANIZAÇÃO. Orleans: UNIBAVE, 2013.

SIQUEIRA, Mirlene Maria M. NOVAS MEDIDAS DO COMPORTAMENTO ORGANIZACIONAL. Porto Alegre: ARTMED, 2014.

VERGARA, Sylvia Constant. PROJetos e Relatórios DE PESQUISA EM ADMINISTRAÇÃO. São Paulo: Atlas, 2010.

Enviado: Março, 2021.

Aprovado: Maio, 2021.

RC: 84729

Disponível em: https://www.nucleodoconhecimento.com.br/administracao/implementacao-daferramenta 
RC: 84729

Disponível em: https://www.nucleodoconhecimento.com.br/administracao/implementacao-daferramenta 